\title{
Paediatric Abdominal Surgical Emergencies in Enugu, South East Nigeria: Any Change in Pattern and Outcome
}

\author{
Chukwubuike Kevin Emeka ${ }^{1,}$, , Nduagubam Obinna Chukwuebuka ${ }^{2}$, Ndu Ikenna Kingsley², \\ Odetunde Oluwatoyin Arinola ${ }^{1}$, Ekenze Sebastin Okwuchukwu ${ }^{3}$, Eze Thaddeus Chikaodili ${ }^{1}$ \\ ${ }^{1}$ Department of Surgery, Enugu State University Teaching Hospital, Enugu, Nigeria \\ ${ }^{2}$ Department of Paediatrics, Enugu State University Teaching Hospital, Enugu, Nigeria \\ ${ }^{3}$ Department of Surgery, University of Nigeria Teaching Hospital, Enugu, Nigeria
}

Email address:

chukwubuikeonline $@$ yahoo.com (C. K. Emeka)

${ }^{*}$ Corresponding author

\section{To cite this article:}

Chukwubuike Kevin Emeka, Nduagubam Obinna Chukwuebuka, Ndu Ikenna Kingsley, Odetunde Oluwatoyin Arinola, Ekenze Sebastin Okwuchukwu, Eze Thaddeus Chikaodili. Paediatric Abdominal Surgical Emergencies in Enugu, South East Nigeria: Any Change in Pattern and Outcome. European Journal of Clinical and Biomedical Sciences. Vol. 5, No. 2, 2019, pp. 39-42. doi: 10.11648/j.ejcbs.20190502.12

Received: May 7, 2019; Accepted: June 10, 2019; Published: June26, 2019

\begin{abstract}
Background: Paediatric abdominal surgical emergencies (PASE) constitute a significant workload of the paediatric surgeon. The objective of this study was to characterize the pattern of PASE in a tertiary hospital in Enugu and determine any change in pattern and outcome. Methodology: This was a retrospective study of children aged 1 day to 16 years who presented with abdominal surgical emergencies to Enugu State University Teaching Hospital (ESUTH), Enugu. Result: There were 152 patients recruited for the study. There were 122 males and 30 females. The mean age at presentation was 6 years while the mean duration of symptoms before presentation to the hospital was 3.5 days. Thirty eight (25\%) patients presented within 48 hours of the onset of their symptoms while 114 patients $(75 \%)$ presented after 48 hours. The emergencies were intussusception $56(36.8 \%)$, typhoid intestinal perforation $30(19.7 \%)$, obstructed hernia $20(13.2 \%)$, appendicitis $17(11.2 \%)$, abdominal trauma $10(6.6 \%)$, neonatal intestinal obstruction $6(4 \%)$, ruptured appendix $6(3.9 \%)$, Hirschsprung's disease $4(2.6 \%)$, adhesive bowel obstruction $2(1.3 \%)$, and Gastroschisis $1(0.7 \%)$. The mean hospital stay was 6.7 days. Thirty four patients (22.4\%) who had surgery developed post-operative complication. The most common complication was surgical site infection and this occurred most in patients who had typhoid intestinal perforation $(\mathrm{P}=0.017)$. There were $12(7.9 \%)$ deaths. Conclusion: In this series, intussusception was the most common paediatric abdominal surgical emergency seen in Enugu unlike in the past when it used to be typhoid intestinal perforation. Mortality was less in the current study. This illustrates a change in pattern and outcome.
\end{abstract}

Keywords: Paediatric, Emergencies, Outcome, Pattern, Abdominal, Change

\section{Introduction}

Acute abdomen is a clinical condition that demands urgent attention and treatment. Broadly speaking, acute abdomen may be caused by infection, inflammation, vascular occlusion or obstruction [1]. Abdominal surgeries constitute a significant number of paediatric emergency surgeries done in our environment. Paediatric abdominal surgical emergency (PASE) is a frequent reason for emergency admission of children and it accounts for $2.4-3.1 \%$ of all paediatric admissions in Nigeria [2]. Mhando et al in 2008 reported that paediatric abdominal surgical emergencies accounted for up to $4 \%$ of all paediatric admissions in Tanzania [3]. Almost all patients that have PASE present with abdominal pain [4]. Centre for Disease control and prevention (CDC) reported that $11 \%$ of emergency room visits in 2008 were for abdominal pain [4]. Nadia et al in 2017 reported that $20 \%$ of children who present with abdominal pain will require surgery [5]. Paediatric abdominal surgical emergencies pose a diagnostic challenge to the clinician due to inability of the children to explain their symptoms and co-operate during physical examination [6]. Again, limited diagnostic tools in 
our setting make paediatric abdominal surgical emergency a major diagnostic task to the paediatric surgeon [6]. The aetiologies of paediatric abdominal surgical emergencies may vary over time or with geographical location [6]. Treatment of PASE should be multidisciplinary involving the paediatricians, paediatric surgeons, radiologists and anaesthetists [7]. High morbidity and mortality seen in developing countries could be attributed to poverty and ignorance which lead to late presentation. The use of herbal drugs, over the counter drugs and religious beliefs also contributes to high morbidity and mortality. The aim of this study was to determine the pattern and outcome of paediatric abdominal surgical emergencies in a tertiary hospital in Enugu, South East Nigeria. Any change in pattern and outcome was also determined.

\section{Methodology}

This was a retrospective study of paediatric patients that presented with abdominal surgical emergencies. The study period was from October 2017 to March 2019. All patients from birth to the age of 16 years who presented to the Paediatric Surgical Unit of Enugu State University Teaching Hospital, Parklane, Enugu, South East Nigeria were recruited into the study. Enugu State University Teaching Hospital serve the whole of Enugu State with a population of about 3 million of which 45 percent are children below the age of 16 years according to national census of 2007. Referrals are also received from neighbouring states. Patients who had surgery at a peripheral hospital for the condition before being referred to us for reoperation were excluded from the study. Data were extracted from the case notes, operation notes, operation register, and admission-discharge records. The information extracted include the age, gender, duration of symptoms before presentation, time interval between presentation and intervention, complications of treatment and outcome. . Ethical approval was obtained from the Ethics and Research committee of Enugu State University Teaching Hospital. Statistical Package for Social Science (SPSS) version 21 was used for data entry and analysis. Data were expressed as percentages. Chi $\left(\mathrm{X}^{2}\right)$ or student's $\mathrm{T}$ test was used to test for significance. $\mathrm{P}$ value $<0.05$ was considered statistically significant.

\section{Results}

\subsection{Demography}

One hundred and sixty two paediatric abdominal surgical emergency cases were seen during the study period but only 152 patients had complete case records and formed the basis of this report. There were 122 males and 30 females, with a male to female ratio of 4: 1. Eight patients were neonates (less than one month old) while 144 patients were older than one month. The mean age at presentation was 6 years (range: 2 days -16 years). The ages of the patients at presentation is shown in table 1.

Table 1. Shows age distribution of the patients at presentation.

\begin{tabular}{lll}
\hline Age at presentation & Number of patients & Percentage (\%) \\
\hline Less than one month & 8 & 5.3 \\
One month to 7 years & 96 & 63.2 \\
8 years to 16 years & 48 & 31.5 \\
\hline
\end{tabular}

The mean duration of symptoms before presentation to the hospital was 3.5 days (1-10 days). Thirty eight (25\%) patients presented within 48 hours of the onset of their symptoms while 105 patients (69\%) presented after 48 hours but within one week of onset of symptoms. The remaining 9 patients $(6 \%)$ presented after one week of the onset of symptoms. The mean duration between presentation and intervention was 1.8 days (1-3 days). The mean hospital stay was 6.7 days (2-14 days).

\subsection{Diagnosis}

Intussusception was the most common cause of paediatric abdominal surgical emergency in our centre accounting for 56 patients $(36.8 \%)$. Typhoid intestinal perforation (TIP) was the second most common condition with 30 patients $(19.7 \%)$, followed by obstructed external hernia which accounted for 20 patients $(13.2 \%)$. Others are as shown in table 2 .

Table 2. Shows the Diagnosis of the patients.

\begin{tabular}{lll}
\hline Diagnosis & Number of Patients & Percentage (\%) \\
\hline Intussusception & 56 & 36.8 \\
Typhoid intestinal perforation & 30 & 19.7 \\
Obstructed external hernias & 20 & 13.2 \\
Appendicitis & 17 & 11.2 \\
Abdominal trauma & 10 & 6.6 \\
Neonatal intestinal obstruction & 6 & 3.9 \\
Ruptured appendix & 6 & 3.9 \\
Hirschsprung's disease & 4 & 2.6 \\
Adhesive bowel obstruction & 2 & 1.3 \\
Gastroschisis & 1 & 0.7 \\
\hline
\end{tabular}

\subsection{Treatment Offered}

One hundred and twenty four patients $(81.6 \%)$ had surgery while 28 patients $(18.4 \%)$ were managed non-operatively. Forty four patients $(28.9 \%)$ had an intervention within 24 hours of presentation while 93 patients $(61.2 \%)$ were treated after 24 hours but within 48 hours. Fifteen patients $(9.9 \%)$ had an intervention after 48 hours.

\subsection{Complications}

Thirty four $(22.4 \%)$ patients who had surgery developed at least one complication. The most common post-operative complication was surgical site infection $17(11.2 \%)$ and this occurred mostly in patients who had typhoid intestinal perforation $(\mathrm{P}$ value $=0.017)$. Other post-operative complications were sepsis $11(7.2 \%)$ and respiratory complications $6(4 \%)$, as shown in figure 1 . 


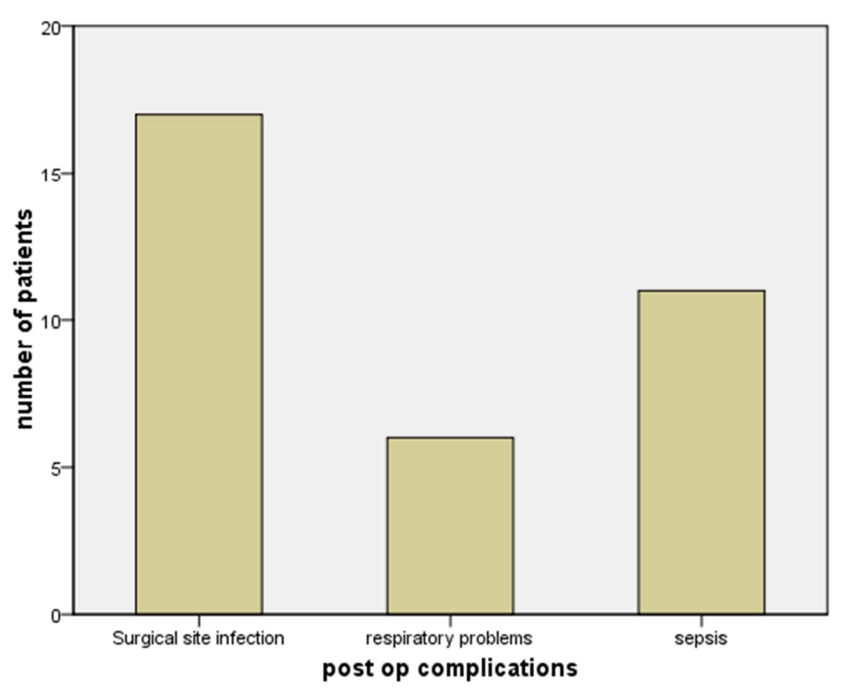

Figure 1. Shows post-operative Complications.

\subsection{Mortality}

There were 12 deaths accounting for $7.9 \%$ of the patients. Most of the deaths occurred amongst the neonates ( $\mathrm{P}$ value $=$ 0.035). Seven neonates, out of 8 , died while five, out of 144 of those older than one month, died (as shown in Table 3 ).

Table 3. Shows the mortality of the patients.

\begin{tabular}{llll}
\hline Age & $\begin{array}{l}\text { Number of } \\
\text { patients }\end{array}$ & $\begin{array}{l}\text { Number that } \\
\text { died }\end{array}$ & $\begin{array}{l}\text { Percentage } \\
(\%)\end{array}$ \\
\hline Neonates & 8 & 7 & 87.5 \\
Older than one month & 144 & 5 & 3.5 \\
\hline
\end{tabular}

\section{Discussion}

Generally, surgical emergencies represent more than 50\% of surgical admissions and constitute a major part of the surgeons' workload in most parts of the world [8]. The range of paediatric abdominal surgical emergencies represents a diverse spectrum of conditions, from congenital to acquired pathologies [3]. Paediatric abdominal surgical emergencies are linked with higher morbidity and mortality when compared with elective surgeries especially in developing countries [9]. This is due to late presentation to healthcare facility and delays in diagnosis and treatment, seen mostly in developing countries [10]. In this study, the authors set out to determine the pattern of paediatric abdominal surgical emergencies in a tertiary hospital in Enugu and sought for change in pattern and outcome in relation to a previous study.

In the current study, there is a male preponderance with a male to female ratio of 4: 1. A study done in Lagos, south west Nigeria had a similar ratio [11]. However, other studies done in northern Nigeria have lower male to female ratio (6, 9). This may be explained by the health altitudes of the people in the different geographical areas where the studies were carried out. The mean age of our patients at presentation was 6 years which is similar to the result of a study done in Ilorin, north central Nigeria [9]. The mean duration of symptoms before presentation to the hospital and the mean duration from presentation to intervention recorded in this study are in agreement to similar studies done elsewhere (9, 10). Late presentation seen in our setting may be explained by poverty and ignorance.

Overall, intussusception accounted for $36.8 \%$ in this series and was the most common paediatric abdominal surgical emergencies in the current study. Other studies are in agreement with our finding $(2,6,9,12,13)$. These studies reported intussusception as the most common cause of mechanical intestinal obstruction in children especially in infants. However, some authors have reported typhoid intestinal perforation as the most common abdominal emergency in children older than one year $(9,14)$, while Li $\mathrm{PH}$ et al and Emily $\mathrm{J}$ et al reported acute appendicitis as the most common PASE $(15,16)$. It is interesting to note that a study done in Enugu, south east Nigeria and published in 2010, reported typhoid intestinal perforation as the most common paediatric abdominal surgical emergency [10]. The difference in the findings of the two studies, done in the same area, may be explained by the recent provision of better drinking water which has reduced the incidence of typhoid intestinal perforation. Typhoid fever is transmitted faecoorally through contaminated food and water due to poor standard of hygiene and unavailability of potable water [17].

Eighteen percent of our patients were treated nonoperatively. This is comparable to what was reported in another study [10]. Such non-operative treatment included hydrostatic reduction of intussusception. Our finding is not similar to earlier reports from Nigeria with regard to postoperative complication rate (9-11). Our complication rate, in the current study, of $22.4 \%$ seems to be the average of the other studies. These wide differences in post-operative complication rates are difficult to explain. When compared with similar studies (9-11), the lower mortality rate of $7.9 \%$ recorded in this study may be attributable to the use of newer potent antibiotics, adequate resuscitation before surgery and close monitoring. In the current study, most of the deaths occurred in neonates. Ademuyiwa et al in their study also reported higher mortality in neonates [11]. Ekenze et al in their own study also recorded a higher mortality in neonates [10]. The transition from foetal life to post natal life is froth with challenges [18]. The stress of anaesthesia and surgery disrupts the delicate balance of the neonatal unique respiratory and cardiovascular physiology. These expose the neonate to electrolyte imbalance, anaemia and other complications that may lead to death [19].

\section{Conclusion}

This study has shown that intussusception has taken over from typhoid intestinal perforation as the most common paediatric abdominal surgical emergency seen in Enugu, south east Nigeria. This difference in the pattern of PASE in Enugu may be due to provision of better drinking water in Enugu metropolis. Apart from intussusception and typhoid intestinal perforation, other cases of PASE, in descending order of frequency, are obstructed hernia, appendicitis, 
abdominal trauma, neonatal intestinal obstruction, ruptured appendix, Hirschsprung's disease, adhesive bowel obstruction, and Gastroschisis. The outcome of paediatric abdominal surgical emergencies has improved due to provision of more potent antibiotics, adequate resuscitation and better peri-operative care. However, morbidity and mortality in neonates are still high. Parenteral nutrition and neonatal intensive care unit are needed provided for further improvements in outcome.

\section{References}

[1] Elhardello OA, MacFie J. Digital rectal examination in patients with acute abdominal pain. Emerg Med J. 2018; 35 (9): 579-580.

[2] Adejuyigbe O, Fashakin EO. Acute intestinal obstruction in Nigerian children. Trop Gastroenterol. 1989; 10: 33-40.

[3] Mhando S, Young B, Lakhoo K. The scope of emergency paediatric surgery in Tanzania. Pediatr Surg Int. 2008; 24: 219-222.

[4] De Burlet K, Lam A, Larsen P, Dennett E. Acute abdominal pain - changes in the way we assess it over a decade. N. Z. Med J. 2017; 130 (1463): 39-44.

[5] Nadia MH, Craig AF. Managing acute abdominal pain in pediatric patients: current perspectives. Pediatric Health, Medicine and Therapeutics. 2017; 8: 83-91.

[6] Abdur-Rahman LO, James OA, Adejuyigbe O. Paediatric surgical abdominal emergencies in a north central Nigerian centre. Annals of Pediatr Surgery. 2012; 8: 25-28.

[7] Mohammed MF, Elbanna KY, Mohammed AME, Murray N, Azzumea F, Almazied G, Nicolam S. Practical Application of Dual-Energy Computed Tomography in the Acute Abdomen. Radiol Clin North Am. 2018; 56 (4): 549-563.

[8] Mai-Phan MA, Patel B, Walsh M, Abraham AT, Kocher HM. Emergency room surgical workload in an inner city UK teaching hospital. World J Emerg Surg. 2008; 3: 19. doi: 10. 1186/1749-7922-3-19.

[9] Abubakar AM, Ofoegbu CP. Factors affecting outcome of emergency pediatric abdominal surgery. Niger J Surg Res. 2003; 3-4: 85-91.

[10] Ekenze SO, Anyanwu PA, Ezomike UO, Oguonu T. Profile of pediatric abdominal surgical emergencies in a developing country. Int Surg. 2010; 95 (4): 319-24.

[11] Ademuyiwa OA, Bode CO, Adesanya OA, Elebute OA. Nontrauma related paediatric abdominal surgical emergencies in Lagos, Nigeria: Epidemiology and indicators of survival. Niger Med J. 2012; 53 (2): 76-79. doi: 10. 4103/0300-1652: 103546 .

[12] Uba AF, Edino ST, Yakubu AA, Sheshe AA. Childhood intestinal obstruction in Northwestern Nigeria. West African Journal of Medicine. 2004; 23: 314-18.

[13] Houben CH, Pang KK, Mou WC, Chan KW, Tam YH, Lee $\mathrm{KH}$. Epidemiology of small bowel obstruction beyond the neonatal period. 2016; 12 (3): 90-93. doi: 10. 1097/01.XPS.0000481055.24776.db.

[14] Abantanga FA, Nimako B, Amoah M. The range of abdominal surgical emergency in children older than 1 year at Komfo Anokye Teaching Hospital, Kumasi, Ghana. 2009; 8 (4): 236242.

[15] Li PH, Tee YS, Fu CY, Liao CH, Wang SY, Hsu YP, Yeh CN, $\mathrm{Wu}$ EH. The Role of Nonconstrast CT in the Evaluation of Surgical Abdomen Patients. Am Surg 2018; 84 (6): 10151021 .

[16] Emily Janitz, Lena Naffaa, Michael Rubin, Srinivas Ganapathy. Ultrasound Evaluation for Appendicitis. Focus on the Pediatric Population: A Review of the Literature. J Am Osteopath Coll Radiol. 2016; 5 (1): 5-14.

[17] Nnabuchi CV, Babalola DI. Incidence and management of typhoid fever in Nigeria. Journal of Obafemi Awolowo University Medical student's Association (IFEMED). 2008; 14 (1): 75-78.

[18] Antonoff M, Marquez T, Saltzman D. Physiology of the newborn. In: Holcomb GW, Murphy JP, editors. Ashcraft's Pediatric Surgery. $5^{\text {th }}$ ed. Philadelphia: Saunders Elsevier; 2010.

[19] Si Ra Bang. Neonatal anesthesia; how we manage our most vulnerable patients. Korean J Anesthesiol. 2015; 68 (5): 434441. doi: 10. 4097/kjae.2015.68.5.434. 